\title{
Sistema colinérgico: revisitando receptores, regulação e a relação com a doença de
} Alzheimer, esquizofrenia, epilepsia e tabagismo

\section{Colinergic system: revisiting receptors, regulation and the relationship with Alzheimer disease, schizophrenia, epilepsy and smoking}

\author{
Ana L. M. Ventura1, Paula A. Abreu1,2, Rodrigo C. C. Freitas¹, Plínio C. Sathler², Natália Loureiro², \\ Helena C. CASTRO ${ }^{2}$ \\ 1 Laboratório de Neuroquímica da Universidade Federal Fluminense (UFF), Niterói, RJ. \\ 2 Laboratório de Neuroquímica e Laboratório de Antibióticos, Bioquímica e Modelagem Molecular (LABioMol) dos Programas de Pós-graduação em Neurociências (EGB), e de Patologia (HUAP) da \\ UFF, Niterói, RJ.
}

Recebido: 5/9/2007 - Aceito: 13/5/2009

\begin{abstract}
Resumo
Objetivo: Revisar a estrutura e o funcionamento do sistema colinérgico central ressaltando seu papel na fisiologia e na fisiopatologia das doenças de Alzheimer e Parkinson, esquizofrenia, epilepsia e tabagismo. Método: Foi realizada uma pesquisa bibliográfica no MedLine, LILACS, PubMed e ISI, e na Biblioteca da Fundação Oswaldo Cruz, RJ, selecionando-se o período de 1914 a 2009, utilizando os descritores: "receptors", "cholinergic", "Alzheimer disease", "schizophrenia", "epilepsy" e "smoking", além de referências cruzadas dos artigos selecionados e análise adicional de referências na literatura específica do tema. Resultados: Efeitos importantes da ativação de receptores colinérgicos nicotínicos e muscarínicos sobre o desenvolvimento do sistema nervoso central (SNC) têm sido descritos. A dessensibilização e a internalização dos receptores acoplados à proteína $\mathrm{G}$ mediadas pela ativação de proteínas cinases têm sido descritas em proliferação, diferenciação e morte celular, além de síndromes neuropsiquiátricas. Conclusão: As informações produzidas a partir de estudos do sistema de neurotransmissão colinérgica podem auxiliar no desenvolvimento de medicamentos mais específicos para o tratamento da doença de Alzheimer, esquizofrenia, epilepsia e tabagismo.
\end{abstract}

Ventura ALM, et al. / Rev Psiq Clín. 2010;37(2):66-72

Palavras-chave: Receptores colinérgicos, doença de Alzheimer, esquizofrenia, epilepsia, tabagismo.

\begin{abstract}
Objective: To review articles regarding important topics about cholinergic system and its ionotropic and G-protein coupled receptors as well as their regulation, also enlightening its importance in central nervous system (CNS) development and in several neuropsychiatric conditions such as Alzheimer disease, schizophrenia, epilepsy and smoking. Method: Bibliographical research was completed through MedLine, LILACS, PubMed, ISI and the Fundação Oswaldo Cruz Library, RJ, specifically for 1914 to 2009, using the descritors: "receptors", "cholinergic", Alzheimer "disease", "schizophrenia", "epilepsy" and "smoking", in addition to the cross-reference of the articles selected and further analyses of bibliographical references on the theme. Results: Currently literature describes important effects of nicotinic and muscarinic receptors activation on development of central nervous system (CNS). The protein G coupled receptors dessensibilization and internalization mediated by kinases have been described in proliferation, differentiation and cell death, and also in neurologic disorders. Discussion: The importance of the cholinergic system and its relationship with pathologies such as Alzheimer disease, schizophrenia, epilepsy is evident. The data produced so far may help on planning medicaments more specific for these pathologies treatment.
\end{abstract}

Ventura ALM, et al. / Rev Psiq Clín. 2010;37(2):66-72

Keywords: Receptors, cholinergic, Alzheimer disease, schizophrenia, epilepsy, smoking.

\section{Introdução}

A acetilcolina (Ach) é um mediador químico de sinapses no sistema nervoso central (SNC), no sistema nervoso periférico e também na junção neuromuscular'. A Ach, seus receptores e o aparato enzimático responsável por sua síntese e degradação constituem o sistema de neurotransmissão colinérgica.

O conhecimento desse sistema, principalmente das vias de sinalização intracelular que se iniciam pela ativação dos receptores colinérgicos, tem sido utilizado no desenvolvimento de novos tratamentos para síndromes neurológicas e psiquiátricas. Nessas síndromes, observa-se uma disfunção do sistema de neurotransmissão colinérgica, como transtornos do humor e alguns tipos de esquizofrenia.

$\mathrm{O}$ aumento de receptores colinérgicos na doença de Parkinson e a redução destes no processo de envelhecimento do SNC, bem como na morte súbita infantil, também já foram descritos na literatura médica.
A relação entre o sistema colinérgico e algumas doenças como a de Parkinson e a esquizofrenia ressalta a importância do bom funcionamento desse sistema.

Neste artigo, pretende-se rever o sistema colinérgico, seus receptores e sua regulação, bem como a participação de neurotransmissores e enzimas importantes no seu funcionamento. Foi incluída nesta revisão a relação entre o sistema colinérgico e alguns quadros patológicos importantes, como as doenças de Parkinson e de Alzheimer, a esquizofrenia, a epilepsia e o tabagismo.

\section{Síntese, captação e liberação da acetilcolina}

A Colina-O-Acetil-Transferase (ChAT) é a enzima responsável pela síntese da Ach a partir de acetil-coenzima A e colina. A glicerofosforilcolina, a fosforilcolina e a fosfatidilcolina geram a colina que é utilizada como substrato e transportada para o SNC através da circulação sanguínea. Assim, as fontes de colina para a síntese de 
Ach provêm da circulação, além da sua recaptação após a liberação e degradação desse neurotransmissor.

Uma vez sintetizada, parte da Ach é transportada e armazenada em vesículas sinápticas. Esse processo é realizado por um transportador vesicular de Ach (VAChT), capaz de elevar em até 100 vezes sua concentração no interior dessas vesículas. Após ser liberada inteiramente por exocitose, a Ach interage especificamente com os receptores colinérgicos presentes nas membranas pré- e póssinápticas ${ }^{2,3}$. A ação da acetilcolina cessa quando é hidrolisada em acetato e colina pela enzima acetilcolinesterase (AChE), presente na fenda sináptica.

Atualmente existem descritos dois tipos de colinesterases que incluem: a) enzimas com alta afinidade para a Ach ligadas à membrana neuronal e presentes em todas as sinapses colinérgicas; b) enzimas com alta afinidade para a butirilcolina, também chamadas de butiril-acetil-colinesterases (BchE) presentes em todos os tecidos (Figura 1).

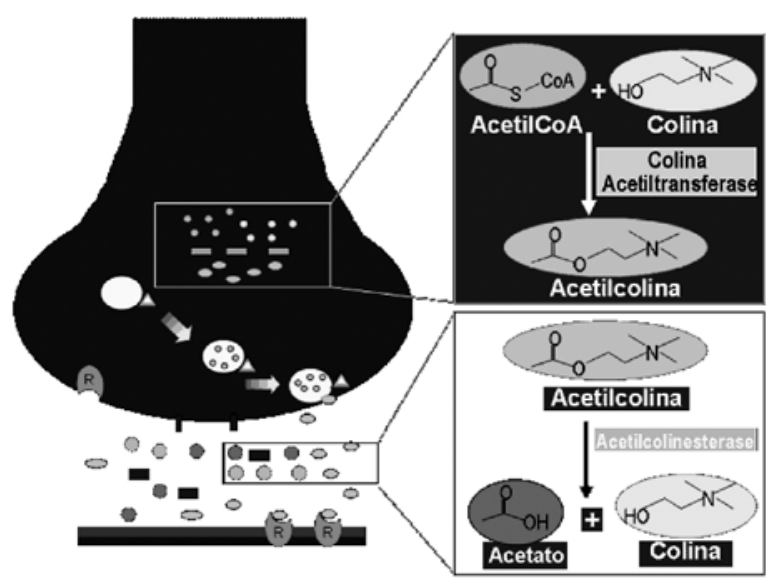

Figura 1. Síntese, liberação, degradação e recaptação da acetilcolina na fenda sináptica. Transportador vesicular de acetilcolina ( $\mathbf{\Delta})$, transportador de colina (D) e receptor de acetilcolina (R).

A AChE é a enzima de maior eficiência catalítica conhecida na atualidade e pode apresentar diferentes isoformas, que podem ser classificadas como globulares ou assimétricas, dependendo da sua conformação espacial. Todas essas formas apresentam uma alta taxa de hidrólise enzimática, de aproximadamente 5.000 moléculas $\operatorname{de} \mathrm{Ach} / \mathrm{s}^{4}$.

\section{Receptores colinérgicos}

Em 1914, Dale ${ }^{5}$ classificou as ações da Ach em muscarínicas e nicotínicas. Essa classificação foi baseada nos subtipos de receptores colinérgicos capazes de se ligar à nicotina e à muscarina, respectivamente, e que respondem à ativação colinérgica com alta afinidade ${ }^{5}$.

\section{Receptores colinérgicos nicotínicos}

Os receptores colinérgicos nicotínicos $(\mathrm{RCN})$ pertencem à família de receptores ionotrópicos que, quando ativados, adquirem a conformação de canal aberto permeável aos íons $\mathrm{Na}+\mathrm{e} \mathrm{K}+{ }^{6}$. Quando comparada à transmissão sináptica induzida por receptores muscarínicos, nota-se que os RCNs medeiam uma transmissão excitatória rápida. Esses receptores são constituídos por cinco subunidades proteicas e estão distribuídos em vários tecidos, incluindo o cérebro e o tecido muscular (Figura 2).

Os RCNs presentes nos músculos são heteropentâmeros constituídos por subunidades $\alpha, \beta, \gamma, \delta$ e $\varepsilon$ (Figura 2), enquanto os receptores do cérebro são formados por várias subunidades $\alpha 2-10$ e $\beta 2-47$. Estes receptores neuronais são constituídos por uma estequiometria geral de $2 \alpha 3 \beta$. Entretanto, $\alpha 7$, $\alpha 8$ e $\alpha 9$ podem formar homo-oligômeros constituídos por um único tipo de subunidade. Em mamíferos, a $4 \beta 2 \mathrm{e}$ o pentâmero homomérico $\alpha 7$ têm propriedades diferentes. $O \alpha 7$, que liga com alta afinidade a $\alpha$-bungarotoxina ( $\alpha$-BTX), uma neurotoxina de veneno de serpente, tem uma dessensibilização rápida e reversível e sua ativação promove um aumento da permeabilidade celular ao cálcio ${ }^{8}$. Já a principal característica do $\alpha 4 \beta 2$ é possuir alta afinidade por nicotina. Os RCNs são amplamente expressos no SNC. Os receptores $\alpha 3$ e $\beta 2$ estão presentes no córtex, no tálamo, no hipocampo e no cerebelo. Já o a 4 é expresso apenas no córtex e no cerebelo, enquanto o a 7 é expresso no córtex, no hipocampo e no tálamo.

A estrutura das subunidades dos RCNs é composta por:

a) um domínio hidrofílico na região $\mathrm{N}$-terminal, posicionado na porção extracelular e que apresenta o sítio de glicosilação envolvido na ligação do agonista, bem como na regulação da dessensibilização e permeabilidade iônica;

b) quatro segmentos hidrofóbicos (19-27 aminoácidos) formando os domínios transmembrana ${ }^{9}$ (Figura 2);

c) um pequeno domínio hidrofílico altamente variável;

d) um domínio C-terminal hidrofóbico de aproximadamente 20 aminoácidos $^{10}$.

e) alças intracelulares compreendidas entre os segmentos transmembranas possuem sítios de fosforilação envolvidos no processo de dessensibilização. Muitas drogas induzem a dessensibilização indiretamente, aumentando os níveis de cálcio intracelular que levam à fosforilação por proteínas cinases sensíveis ao cálcio. Os sítios de ligação aos agonistas parecem estar localizados na região de interface entre as subunidades, enquanto os sítios para ligantes alostéricos não competitivos localizam-se diretamente nas subunidades.

Os RCNs localizados no cérebro distribuem-se nas regiões pré-, pós-, peri- e extrassinápticas, podendo modular a liberação de neurotransmissores e, consequentemente, a atividade sináptica neuronal. Os RCNs têm importância em diversos processos, como o aprendizado e a memória, o desenvolvimento neuronal e participa do sistema de recompensa ${ }^{11}$. Essa versatilidade funcional se correlaciona com as diferentes estruturas que esses receptores possuem nas diversas áreas do sistema nervoso. Como exemplos, podem-se citar receptores com subunidades $\alpha_{3} \alpha_{5} \beta_{4}$ que regulam a transmissão ganglionar e receptores com a subunidade $\alpha 4$ que regulam parcialmente a liberação de dopamina e de glutamato. Já receptores localizados na região estriatal que possuem a subunidade $\beta 3$ alteram a atividade motora por modular a liberação de dopamina, enquanto receptores com a subunidade $\beta 2$ controlam a liberação de GABA e a resposta de neurônios dopaminérgicos no mesencéfalo. Uma disfunção do gene que sintetiza a subunidade $\beta 2$ é responsável pela atrofia do córtex e perda de neurônios, o que sugere que os RCNs estejam envolvidos em processos de sobrevivência de neurônios, além da fisiologia e manutenção dos circuitos sinápticos neuronais ${ }^{12}$.

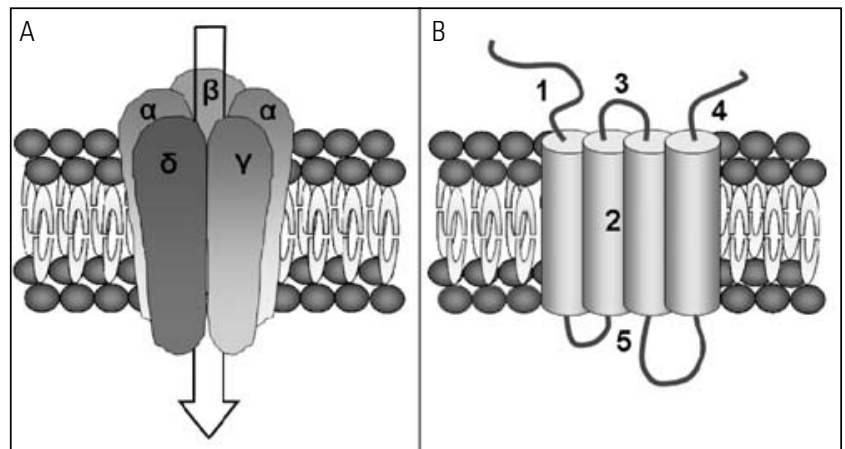

Figura 2. Receptor colinérgico nicotínico $A$ - Subunidades $\alpha, \beta, \gamma$ e $\delta$. B - Domínios presentes em cada subunidade: N-terminal hidrofílico (1), quatro segmentos hidrofóbicos transmembrana (2), domínio hidrofílico variável (3), C-terminal hidrofóbico (4) e alças intracelulares formando sítios de fosforilação (5). 
Os RCNs regulam a liberação e a ativação de neurotransmissores nas regiões pré- e pós-sinápticas, respectivamente, podendo controlar a eficácia da transmissão sináptica. A atuação dos RCNs nos processos de memória e aprendizado indica sua participação na fisiopatologia e nos processos inflamatórios característicos da doença de Alzheimer ${ }^{13}$ e o uso simultâneo de antagonistas nicotínicos e de receptores glutamatérgicos do tipo N-metil-D-aspartato (NMDA) tem atenuado ataques epilépticos induzidos em ratos e camundongos, o que sugere uma íntima relação entre os sistemas de neurotransmissão colinérgico e de NMDA na atividade excitatória do $\mathrm{SNC}^{14}$. O comprometimento da atividade cooperativa entre RCN e receptores dopaminérgicos na região mesoestriatal pode estar envolvido em algumas disfunções neurológicas que predispõem pacientes à doença de Parkinson ${ }^{15}$.

\section{Receptores colinérgicos muscarínicos}

Os receptores colinérgicos muscarínicos (RCMs) também são amplamente distribuídos por diversos sistemas biológicos, onde participam de várias funções vitais ${ }^{3}$. A ativação desses receptores no sistema nervoso periférico tem ações que incluem a redução da frequência e força da contração cardíaca, o relaxamento de vasos sanguíneos periféricos e a constrição das vias respiratórias (brônquios e bronquíolos). No SNC, estão envolvidos no controle da função extrapiramidal, vestibular, em funções cognitivas como memória, aprendizado e atenção, em respostas emocionais, na modulação do estresse, no sono e na vigília.

O conhecimento das funções dos RCMs e de seus subtipos avançou consideravelmente após a clonagem de seus cinco genes distintos (M1-M5) em células de mamíferos ${ }^{16}$. Enquanto a expressão heteróloga de RCMs em diferentes linhagens celulares favoreceu a descoberta das vias de sinalização intracelular envolvidas, os anticorpos específicos permitiram a localização tecidual e celular dos subtipos de RCMs em diferentes organismos. A identificação dos cinco genes que codificam os RCMs permitiu ainda a localização dos sítios de expressão de RNAm desses receptores em diferentes tecidos.

A utilização de agentes farmacológicos seletivos para RCMs tem contribuído para o entendimento da função e regulação desses receptores. Riker e Wescoe ${ }^{17}$ foram os primeiros a demonstrar a existência de diferentes subtipos de RCMs, ao evidenciarem as propriedades cardiosseletivas da galamina, um antagonista muscarínico ${ }^{17}$. Em 1976, Barlow et al. ${ }^{18}$ demonstraram diferenças significativas nas propriedades farmacológicas de RCMs entéricos e atriais de cobaias, enquanto estudos sobre a seletividade da ligação de drogas a RCMs e suas diferenças funcionais no organismo contribuíam para sua comprovação in vivo ${ }^{18}$.

Entre os cinco subtipos de RCMs clonados (M1, M2, M3, M4, M5), apenas o subtipo M5 ainda não foi totalmente caracterizado no nível farmacológico e funcional. Todos os RCMs pertencem à superfamília de receptores acoplados à proteína $\mathrm{G}$ e estruturalmente são proteínas de membrana contendo sete domínios transmembranares (Figura 3). Sítios de ligação específicos para Ach, agonistas e antagonistas muscarínicos estão presentes na região $\mathrm{N}$-terminal e nas alças extracelulares. A presença de um ou mais sítios de glicosilação no N-terminal, como nos receptores M2, reforça a evidência da localização extracelular dessa porção da molécula19. Na região intracelular, os RCMs conservam a região C-terminal, além de três alças intracelulares (i1, i2 e i3) ${ }^{19}$. A diferença funcional na ativação dos diferentes subtipos de RCMs reside principalmente na constituição da alça i3 desses receptores (Figura 3). A i3 é a região dos receptores muscarínicos que interage com a proteína $\mathrm{G}$ e apresenta variação na sequência de aminoácidos entre os RCMs. Já as alças il e i2 são bastante conservadas em todos os subtipos. Os 18 primeiros aminoácidos presentes na região i3 dos receptores M2 e M4 possuem um alto grau de homologia enquanto, nos receptores M1, M3 e M5, essa região é idêntica. Com base nesse padrão de homologia, os RCMs foram divididos em dois grupos: a) receptores M1/M3/M5 e b) receptores $\mathrm{M} 2 / \mathrm{M} 4{ }^{20}$.

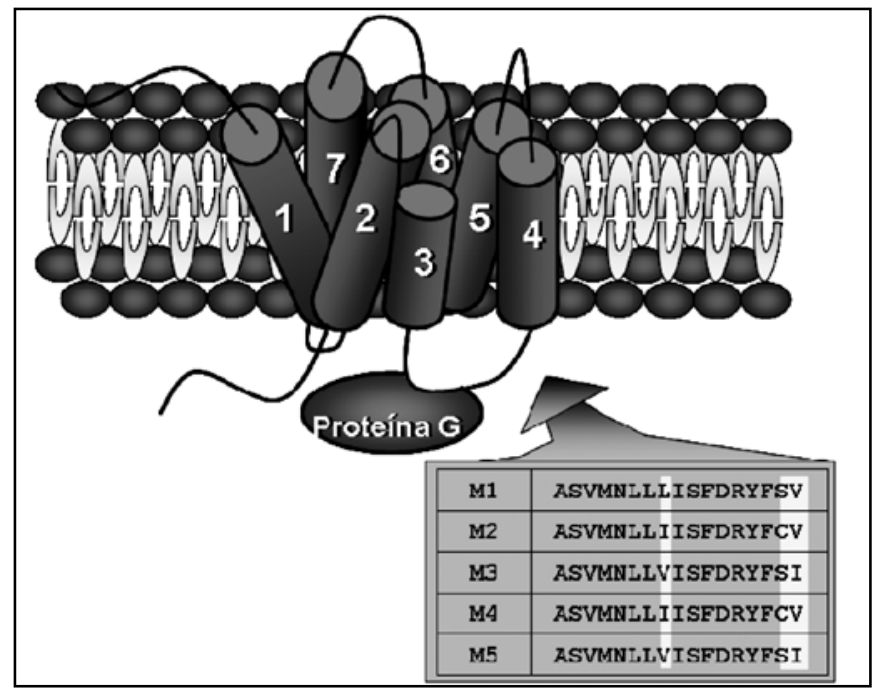

Figura 3. Receptor colinérgico muscarínico mostrando os sete domínios transmembrana e a alça de ligação à proteína G. Em zoom, parte da sequência de aminoácidos dessa alça importante para a ligação à proteína $\mathrm{G}$, revelando os aminoácidos homólogos entre as classes de receptores $M 1$, M3 e M5 e entre M2 e M4, marcados em cinza-claro.

A variação da sequência de aminoácidos na alça i3 nos dois grupos de receptores muscarínicos provavelmente determina o acoplamento distinto à proteína $\mathrm{G}$, justificando os diferentes mecanismos de regulação da resposta celular. Os receptores muscarínicos M1, M3 e M5, quando ativados por agonistas colinérgicos, acoplam-se preferencialmente com a proteína $\mathrm{Gq} / 11$, induzem a ativação da fosfolipase $\mathrm{C}$, que promove a hidrólise de fosfoinositídeos presentes na membrana e a produção de diacilglicerol e inositol trifosfato (segundos mensageiros) ${ }^{21}$. De forma diferenciada, os receptores muscarínicos M2 e M4, quando ativados, acoplam-se preferencialmente à proteína $\mathrm{G}$ inibitória, $\mathrm{Gi} / \mathrm{o}$, que inibe a atividade da adenilciclase e reduz os níveis intracelulares de AMP cíclico ${ }^{22}$.

\section{Os subtipos de receptores colinérgicos muscarínicos}

Os RCMs apresentam características funcionais e de localização que os diferenciam significativamente:

Receptores M1: no SNC, constituem cerca de 50\% dos RCMs presentes no hipocampo e foram localizados, por análises de hibridização in situ, na região do giro denteado, no bulbo olfatório, nas amígdalas e no córtex piriforme ${ }^{23}$. Recentemente, foi demonstrado que são estimulados por carbacol, um agonista colinérgico, e ativam as cinases reguladas por sinais extracelulares (ERKs) em fatias de hipocampo de camundongos. Isso foi confirmado pelo pré-tratamento com pirenzepina, um antagonista colinérgico, que aboliu a ativação das ERKs nessa região do sistema nervoso. Estudos semelhantes demonstraram a deficiência na ativação das ERKs 1 e 2 em neurônios corticais de camundongos "knockout" para receptores M1. O inositol-1,4,5-trifosfato( $\left(\mathrm{IP}_{3}\right)$ é uma molécula formada pela ação da fosfolipase $\mathrm{C}$ sobre fosfolipídios de membrana, atuando, portanto, como um segundo mensageiro. A indução da produção de $\mathrm{IP}_{3}$ por carbacol se mostrou $60 \%$ menor nos neurônios corticais dos camundongos "knockout", quando comparada com neurônios de camundongos normais, sugerindo que a ativação das ERKs 1 e 2 induzida por carbacol é mediada por receptores M1 acoplados à ativação da fosfolipase $\mathrm{C}^{24}$.

Receptores M2: no SNC, foram localizados principalmente em neurônios estriatais, no tegumento mesopontino e no núcleo motor do nervo craniano. A localização da imunorreatividade para esse receptor é semelhante ao padrão de imunorreatividade para neurônios colinérgicos no SNC, o que aponta esse subtipo de receptor como um autorreceptor nesse tecido ${ }^{25}$. 
Estudos sobre a ação dos receptores M2 na fisiologia do coração mostram a ativação da óxido nítrico sintase (eNOS) em miócitos em várias espécies. Entretanto, é necessária a translocação dos receptores M2 e da eNOS para compartimentos subcelulares especializados, chamados cavéolas, para viabilizar esse processo. A produção de óxido nítrico induzida pelos receptores M2 pode ser um dos fatores que contribui para a resposta ionotrópica negativa geralmente observada após estimulação colinérgica do tecido cardíaco.

A ativação de receptores $M 2$ reduz a força de contração e também a frequência de batimentos cardíacos em cobaias, o que está associado à inibição de canais de $\mathrm{Ca}^{2+}$ voltagem dependente e à ativação de canais retificadores de $\mathrm{K}+$ através da estimulação da Gi/o ${ }^{22}$. Wang et al. ${ }^{26}$ mostraram a relação entre a ativação de receptores M2 e a regulação de canais iônicos de cálcio e de cloreto ${ }^{26}$. A estimulação de receptores M2 transfectados transitoriamente em oócitos de Xenopus promoveu a abertura de canais de $\mathrm{Cl}$ - dependentes de voltagem, um efeito dependente da ativação da PI-3-cinase, demonstrando uma nova via de sinalização intracelular iniciada por receptores M2. Essa via pode ser alternativa ao tradicional acoplamento desse subtipo de receptor à via $\mathrm{Gi} / \mathrm{o}$.

Receptores M3: segundo análises de imunocitoquímica, hibridização "in situ” e autorradiografia, estão presentes em várias regiões cerebrais que incluem o núcleo estriado, hipocampo, núcleo talâmico anterior, colículo superior, núcleo pontiforme, região límbica cortical e camadas superficiais do neocórtex ${ }^{23}$. Os dados sugerem que esses receptores medeiam vários processos colinérgicos no cérebro que incluem a formação de memória, aprendizado, o controle da função motora e o comportamento social.

Os receptores $\mathrm{M} 3$ expressos transitoriamente em células $\mathrm{CHO}$, uma linhagem celular produzida a partir do ovário de hamster chinês, também estão envolvidos na ativação de proteínas cinases ativadas por mitógenos (MAPKs), uma vez que agonistas como oxotremorine-M e pilocarpina mimetizam a ativação dessa enzima induzida por acetilcolina. Esse efeito é bloqueado por inibidores de proteína cinase-dependente de cálcio (PKC) e mimetizado por agonistas seletivos para receptores M1 e M5, sugerindo que nessas células a via de sinalização intracelular para ativar as MAPKs integra a ativação dos subtipos de receptores muscarínicos M1, M3 e M5, bem como sua consequente mobilização de $\mathrm{IP}_{3}$ e da $\mathrm{PKC}^{27}$.

Receptores M4: são abundantes em neurônios estriatais de ratos, mas também estão presentes no hipocampo de roedores. Compõem importantes vias de sinalização inibitória ou estimulatória para a formação da memória, juntamente com receptores M1 e M223.

De forma interessante, o RNAm para os receptores M4 foi localizado no núcleo caudado, putâmen e nas camadas plexiformes do bulbo olfatório. Kimura e Baughman ${ }^{28}$ demonstraram que receptores M4 modulam negativamente potenciais pós-sinápticos excitatórios em neurônios corticais de ratos, uma vez que antagonistas específicos de receptores M4 bloqueiam a inibição da acetilcolina sobre esses potenciais ${ }^{28}$. Eles ainda observaram que receptores M1 modulam negativamente os potenciais pós-sinápticos inibitórios desses neurônios. Dessa forma, a separação das ações da acetilcolina no córtex cerebral, através da discriminação de seus subtipos de receptores, favorece a intervenção farmacológica seletiva em alguns distúrbios neurológicos que envolvem a neurotransmissão colinérgica.

Receptores M5: são os menos caracterizados quando comparados com os demais subtipos. A sua localização no SNC é determinada principalmente pela distribuição do seu RNAm. Algumas evidências demonstram a existência de expressão endógena de receptores M5 em células do melanoma humano A2058. Essas células são um modelo de estudo em potencial para a sinalização intracelular iniciada pelos receptores M5, visto que sua estimulação produz tanto a liberação de ácido araquidônico quanto a inibição do acúmulo de AMP-cíclico (AMPc) induzido por forscolina, um ativador de adenilciclase. A linhagem de células da leucemia eosinofílica (EoL-1) é outro sistema celular que pode ser utilizado para o estudo dos receptores M5 endógenos. Nessas células, a expressão de RNAm para receptores M5 e M3 é aumentada na presença de interferon, o que é necessário para a diferenciação das células EoL-1 em macrófagos maturos ${ }^{29}$.

\section{Regulação de receptores acoplados à proteína $G$}

Atualmente, os três mecanismos de regulação da resposta celular induzida por ativação de receptores acoplados à proteína $\mathrm{G}$ são: $i$ ) a dessensibilização, ii) a internalização ou sequestro de receptores, e iii) a diminuição do número de receptores ou downregulation ${ }^{30}$.

\section{Dessensibilização}

A dessensibilização está diretamente relacionada com a diminuição na geração de segundos mensageiros induzida pela ativação do receptor pelo agonista e tem como pré-requisitos: $i$ ) ativação prolongada do receptor por seu agonista, $i$ ) fosforilação do receptor por proteínas cinases dependentes de receptores acoplados à proteína $\mathrm{G}$ (GRKs) ou dependentes de segundos mensageiros como a PKA ou PKC e iii) ligação ao receptor de uma classe de proteínas citosólicas, as arrestinas $^{31}$. Na dessensibilização, a diminuição da capacidade responsiva do receptor ocupado pelo agonista pode ocorrer afetando (dessensibilização heteróloga - fosforilação dos receptores pelas proteínas cinases dependentes de segundos mensageiros) ou não (dessensibilização homóloga - ativação de GRKs) outros receptores não estimulados e presentes na mesma célula ${ }^{32}$.

\section{Internalização e reciclagem}

O processo de internalização ou sequestro de receptores acoplados à proteína G é mais um nível de regulação da atividade desses receptores quando estimulados pelo agonista. Estudos utilizando o receptor $\beta 2$-adrenérgico como modelo têm demonstrado que a exposição ao agonista promove a translocação desses receptores da superfície celular para compartimentos intracelulares ${ }^{30}$. A internalização de receptores é não só um mecanismo para a dessensibilização, mas também para sua ressensibilização desses receptores ${ }^{30}$. A recuperação da atividade de receptores se dá principalmente por um processo de reciclagem dos receptores previamente internalizados, que parece ser constitutivo na maioria das células. Nessa reciclagem, os receptores fosforilados pelas GRKs e internalizados em vesículas intracelulares são defosforilados por fosfatases, que têm sua ação favorecida pela diminuição do $\mathrm{pH}$ das vesículas. Os receptores são então posteriormente reinseridos na membrana, onde se tornam aptos para um novo ciclo de regulação ${ }^{30}$.

A internalização de receptores acoplados à proteína $\mathrm{G}$ influi diretamente na distribuição celular e subcelular desses receptores. Essa distribuição pode ser determinada por quatro vias de tráfego intracelular. Geralmente, os receptores recém-sintetizados provenientes do complexo de Golgi são direcionados para a superfície celular. Entretanto, além de compor um estoque de reserva intracelular, os receptores presentes nos endossomas podem ser reciclados para a membrana plasmática ou seguir para a fusão com lisossomas, onde serão degradados. Nas células não estimuladas por agonistas, esse tráfego intracelular de receptores se apresenta relativamente lento, sendo drasticamente acelerado na presença de agonistas.

A literatura descreve duas vias de internalização de receptores acoplados à proteína $\mathrm{G}$ mediada por: a) clatrina e b) cavéolas. A via mediada por clatrina tem sido a mais estudada, sendo comprovada experimentalmente como responsável pela internalização de vários receptores, incluindo os receptores $\beta 2$-adrenérgicos, muscarínicos e de endotelina $\mathrm{A}^{33}$. Goodman et al. ${ }^{34}$ observaram que a ligação da arrestina ao receptor fosforilado promove o recrutamento e a ligação da proteína clatrina a esse complexo (Figura 4), que se polimeriza, promovendo o recobrimento da membrana e a formação de vesículas intracelulares contendo complexos proteicos que incluem o receptor, a arrestina e proteínas cinases ${ }^{34}$. Recentemente, foi demonstrada que a arrestina pode promover o recrutamento de enzimas tirosina-cinases da família das Src e, consequentemente, induzir a formação do complexo receptor acoplado à proteína $\mathrm{G}$-tirosina-cinase Src. A ativação da tirosina cinase Src é essencial para a ativação de proteínas cinases ativadas por mitógenos (MAPKs). A internalização de receptores acoplados à proteína $\mathrm{G}$ induzida por seus agonistas específicos via 


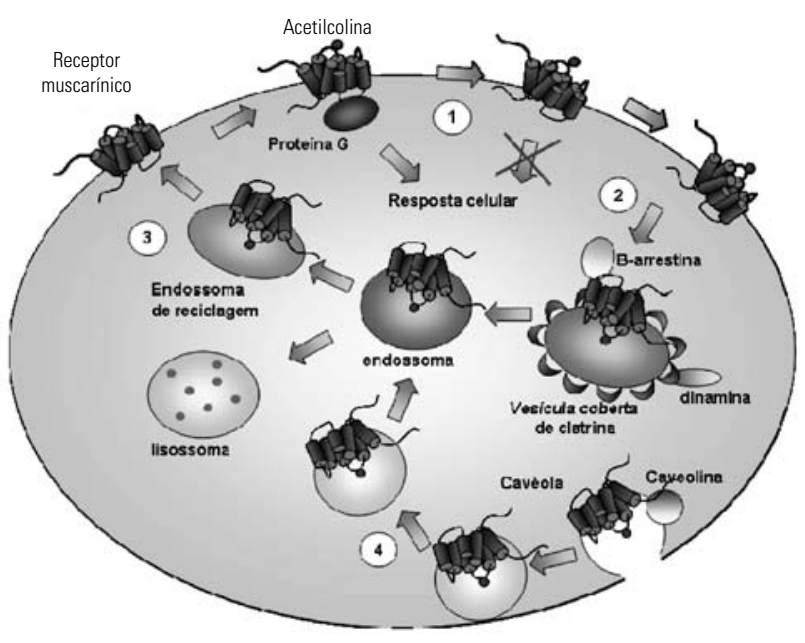

Figura 4. Regulação do receptor muscarínico acoplado à proteína G, ressaltando os mecanismos de dessensibilização (1), internalização via clatrina (2), ressensibilização (3) e internalização via cavéolas (4).

clatrina aparentemente regula a resposta celular diante do estímulo do agonista, promovendo uma segunda onda de sinalização celular envolvendo a ativação das MAPKs.

Recentemente, tem sido observada a correlação funcional entre a internalização e a transdução de sinal induzida por diversos receptores de neurotransmissores, incluindo aqueles acoplados à proteína $\mathrm{G}$, em pequenas invaginações vesiculares $(50-100 \mathrm{~nm}$ ) da membrana plasmática, denominadas cavéolas (Figura 4). Essas estruturas funcionam como subcompartimentos da membrana celular especializados no tráfego de proteínas e em mecanismos de transdução de sinal mediados por receptores.

\section{Downregulation}

Enquanto a dessensibilização refere-se à diminuição da atividade dos receptores sem alteração do seu número total, a downregulation implica a diminuição de receptores por meio da redução da síntese, da internalização com degradação em lisossomos ou degradação não lisossômica de receptores ${ }^{35}$.

Diferentes mecanismos podem induzir downregulation, incluindo a modulação da expressão gênica. Experimentos revelam que o número de receptores presentes em uma célula pode ser regulado por meio do nível de expressão gênica, bem como o de biossíntese e de degradação destes. É possível observar ainda a diminuição dos receptores M2 e M4 presente nos dendritos como também a diminuição de receptores M2 aderidos à membrana, após uma estimulação neuronal colinérgica crônica, indicando que esses receptores foram downregulados. A diminuição do RNAm de receptores M2 no núcleo basal de Meynart e em neurônios estriatais de camundongo cujos níveis de ACh são cronicamente elevados explica parcialmente a perda dos receptores M4 dos dendritos ${ }^{35}$.

A downregulation pode resultar em um aumento da proteólise de proteínas $G$ acopladas a receptores. Para os receptores $\beta 2$-adrenérgicos, acredita-se que a proteólise é o mecanismo de downregulation predominante ${ }^{35}$.

\section{Doenças relacionadas ao sistema colinérgico}

Doença de Alzheimer: a relação entre o sistema colinérgico e a demência do tipo Alzheimer tem sido explorada desde os anos 1980. Essa é uma doença neurodegenerativa de instalação insidiosa e progressiva. Modificações neuroquímicas primárias no sistema colinérgico têm sido observadas em cérebros de doentes de Alzheimer, sugerindo uma disfunção colinérgica envolvida nas alterações de memória, aprendizagem, atenção e outros processos cognitivos comuns afeta- dos nesses pacientes ${ }^{36}$. Alterações tanto na quantidade de receptores muscarínicos em diversas regiões cerebrais quanto na sinalização intracelular induzida por esses receptores, como a presença de altas concentrações de uma proteína denominada inibidor endógeno de baixo peso molecular (IEBP), já foram descritas. O IEBP proporciona um antagonismo endógeno aos receptores colinérgicos muscarínicos nesses pacientes que parece se relacionar às manifestações clínicas observadas nessa neuropatia degenerativa.

O tratamento da doença de Alzheimer requer intervenções farmacológicas visando sua fisiopatologia específica e este inclui o uso de agentes farmacológicos que melhoram os sintomas específicos (como ilusões e distúrbios do sono) e intervenções comportamentais que possam melhorar os sintomas e as atividades diárias do paciente. Os inibidores da AChE (tacrina e donepezil) que permitem um aumento nos níveis cerebrais de acetilcolina ${ }^{37}$ e recentemente um antagonista não competitivo de receptor de NMDA (memantina), o qual está indicado para as formas moderadas a graves da doença, são os únicos fármacos atualmente aprovados pelo FDA (U.S. Food and Drug Administration) para o tratamento da doença de Alzheimer.

Estudos demonstram que a tacrina é eficaz não apenas em melhorar a cognição, mas também os distúrbios neuropsiquiátricos dos pacientes como apatia e ansiedade. Por ser hepatotóxica, necessita-se de realização de provas de função hepática e ajustes da dose. O donepezil apresenta menos efeitos colaterais e não exige monitorização bioquímica para disfunção hepática ${ }^{38}$.

Os efeitos colaterais desses medicamentos incluem náuseas, vômitos, diarreia, bradicardia e tontura relacionados com a dose. As contraindicações ao tratamento com inibidores da colinesterase incluem hepatopatia, alcoolismo, doença ulcerosa péptica, doença pulmonar obstrutiva crônica e bradicardia. Tais agentes podem estabilizar o estado do paciente por um período de meses.

Uma depressão leve a moderada é comum nos estágios iniciais da doença e pode responder à medicação antidepressiva, como os inibidores seletivos da recaptação da serotonina (ISRS) e antidepressivos tricíclicos com baixos efeitos colaterais anticolinérgicos (desipramina e nortriptilina). As convulsões generalizadas devem ser tratadas com anticonvulsivantes apropriados, como fenitoína ou carbamazepina, enquanto a agitação pode ser tratada com fenotiazinas (como tioridazina), haloperidol, risperidona e benzodiazepínicos (como lorazepam). O haloperidol em baixas doses, a trazona, a buspirona, o propranolol e a olanzapina podem ser os mais úteis como também os que apresentam menos efeitos colaterais ${ }^{38}$. As intervenções comportamentais são essenciais no tratamento dos pacientes com doença de Alzheimer. O controle do ambiente, com o propósito de manter a casa do paciente segura e facilitar a locomoção interna, pode ajudá-lo.

Epilepsia: a epilepsia no lobo frontal é resultado de uma mutação da serina 248 por uma fenilalanina na subunidade $a 4$ do domínio transmembrana do receptor nicotínico, o que leva a uma redução da permeabilidade ao cálcio, redução na abertura do canal e rápida dessensibilização ${ }^{39}$. A concentração de agonista capaz de induzir a dessensibilização desses receptores mutantes é 3 mil vezes mais baixa. Nos pacientes com epilepsia, a rápida dessensibilização de RCN $\alpha 7$ aumenta enormemente. A mutação da leucina 250 pela threonina em receptores $\alpha 7$ conhecidos por reduzir a dessensibilização do canal aumenta a sensibilidade à apreensão induzida por nicotina em ratos, o que sugere um papel importante da dessensibilização do RCN $\alpha 7$ nos modelos de epilepsia.

A carbamazepina ou a fenitoína são atualmente os fármacos de escolha inicial para o tratamento das convulsões parciais ${ }^{14}$, incluindo as que apresentam generalização secundária. $\mathrm{O}$ uso da fenitoína em longo prazo associa-se com efeitos estéticos indesejáveis como hirsutismo, feições grosseiras e hipertrofia gengival. A carbamazepina pode causar leucopenia, anemia aplásica ou hepatotoxicidade. O ácido valproico é uma alternativa eficaz para alguns pacientes com convulsões parciais, especialmente com generalização secundária e raramente causa supressão reversível da medula óssea e hepatotoxicidade. A lobectomia temporal ainda tem sido um tratamento de escolha para os casos resistentes a fármacos. 
Tabagismo: a nicotina presente no tabaco é um agonista seletivo de RCN e, assim como outras drogas capazes de causar dependência, está diretamente envolvida na liberação de dopamina na região mesolímbica. A tolerância à nicotina observada em fumantes, bem como os sintomas de abstinência, ocorre por dessensibilização e upregulation dos RCNs após a exposição crônica. A nicotina chega às sinapses neurais através da barreira hematoencefálica, alcançando concentrações de 50-600 nM, que é muito menor do que as concentrações fisiológicas de ACh necessárias para gerar um potencial de ação $(1 \mathrm{mM})$. Entretanto, a nicotina persiste por não ser degradada pela AChE e essa exposição prolongada pode promover dessensibilização após ativação transiente ${ }^{40}$. O uso crônico da nicotina pode resultar em um aumento do número de receptores associado a uma desativação funcional, o que se sugere ser o mecanismo responsável pelos efeitos de dependência à nicotina ${ }^{40}$.

Três medicamentos são aprovados pela Food and Drug Administration para o tratamento do tabagismo: a nicotina, a bupropiona e a vareniclina ${ }^{41}$. Além desses, a nortriptilina e clonidina mostraram-se mais eficientes do que placebo em ensaios clínicos controlados. Há cinco produtos para reposição de nicotina: goma de mascar, pastilhas e comprimidos, sistemas adesivos transdérmicos, inalador e spray. Os efeitos da goma de mascar são basicamente locais e incluem fadiga mandibular, irritação da boca e da garganta, desconforto gástrico e soluços. Os sistemas transdérmicos são aplicados pela manhã e removidos na manhã seguinte ou ao deitar-se, dependendo do produto. O spray nasal de nicotina pode causar irritação local do nariz, o que comumente provoca sensação de queimação, espirros e lacrimejamento no início do tratamento, mas sobrevém tolerância a esses efeitos em um a dois dias. $\mathrm{O}$ inalador fornece nicotina à garganta e às vias aéreas superiores, de onde é absorvida da mesma forma como na goma de mascar, sendo comercializado como um dispositivo de plástico em forma de cigarro, sendo usado sem restrição.

A bupropiona, também comercializada como antidepressivo, pode ser associada ao uso do adesivo de nicotina. Os antidepressivos são mais eficazes naqueles com antecedentes de sintomas de depressão ${ }^{41}$. No entanto, apesar de evidências mostrarem a eficácia desses medicamentos, a maioria dos pacientes não adere totalmente ao tratamento e, portanto, novas opções terapêuticas são necessárias.

O tartrato de vareniclina é uma nova droga produzida a partir de um alcaloide natural da planta Cytisus laburnum, a cistisina. Com efeito de agonista parcial dos receptores nicotínicos neuronais $\alpha 4 \beta 2$, a vareniclina foi desenvolvida especialmente para o tratamento do tabagismo. Esse composto se liga com elevada afinidade e seletividade aos nAChR $\alpha 4 \beta 2$, onde atua como agonista parcial, possuindo tanto atividade de agonista, com eficácia intrínseca inferior à da nicotina, como atividade antagonista na presença da nicotina ${ }^{42}$.

Estudos eletrofisiológicos e neuroquímicos demonstraram que a vareniclina, quando se liga aos receptores nicotínicos neuronais a4 $\beta 2$ da acetilcolina, estimula a atividade mediada por estes, mas a um nível significativamente inferior ao da nicotina, uma vez que esta compete por um mesmo sítio de ligação no receptor $\mathrm{nAChR}$ $\alpha 4 \beta 2$, para o qual a vareniclina tem a maior afinidade. Assim, a vareniclina pode efetivamente bloquear a capacidade da nicotina de ativar completamente os receptores a $4 \beta 2$ e o sistema mesolímbico dopaminérgico ${ }^{43}$.

A eficácia da vareniclina na cessação tabágica resulta da atividade agonista parcial desta sobre os receptores nicotínicos $\alpha 4 \beta 2$, nos quais a sua ligação produz um efeito suficiente para aliviar os sintomas de abstinência e dependência (atividade agonista) e simultaneamente resulta na redução dos efeitos compensatórios e de reforço do tabaco, pela prevenção da ligação da nicotina aos receptores $\alpha 4 \beta 2$ (atividade antagonista $)^{43}$. Essa droga é absorvida bem via oral, atingindo concentrações plasmáticas em 2 a 4 horas. Sua vida média é de 20 a 30 horas, sendo eliminada $80 \%$ na urina após a metabolização.

Esquizofrenia: O envolvimento dos RCNs na esquizofrenia foi sugerido devido à grande proporção de esquizofrênicos fumantes (90\%), em comparação com os $30 \%$ de fumantes na população geral ${ }^{9}$. Altos níveis de anticorpos anti-RCN foram encontrados em pacientes com esquizofrenia, o que poderia contribuir para a redução no núme- ro de receptores observado. O uso de nicotina nesses pacientes pode ser uma tentativa de compensar a redução na neurotransmissão em RCN e pode auxiliar os pacientes a compensar o déficit cognitivo e os distúrbios de atenção. O defeito está relacionado ao polimorfismo no cromossomo 15, que é lócus para a subunidade $\alpha 7$. Além disso, é observada uma redução da subunidade $\alpha 7$ no córtex frontal nesses pacientes, o que reforça sua importância na esquizofrenia.

Apesar do envolvimento de receptores colinérgicos nessa doença, os antipsicóticos são considerados a base do tratamento agudo e de manutenção da esquizofrenia. O bloqueio do receptor dopaminérgico do sistema límbico e dos núcleos da base parece ser um elemento fundamental, uma vez que as potências clínicas dos antipsicóticos tradicionais, como o haloperidol e a clorpromazina, acompanham suas afinidades pelo receptor D2 de dopamina e, mesmo os agentes mais novos, os chamados "atípicos", em função do menor espectro de efeitos colaterais, exercem algum grau de bloqueio no receptor D2. Contudo, a eficácia clínica dos neurolépticos atípicos pode envolver o bloqueio dos receptores dopaminérgicos D1, D3 e D4, a atividade a 1 e $\alpha 2$-noradrenérgica e/ou a alteração da relação entre a atividade dos receptores $5 \mathrm{HT} 2$ e D244.

A farmacoterapia inicial da psicose deve começar com a administração de agentes antipsicóticos atípicos, tais como a clozapina, a risperidona, a olanzapina ou a quetiapina ${ }^{45}$. Contudo, $\mathrm{o}$ antipsicótico atípico padrão é a clozapina, um dibenzodiazepínico de potência maior em bloquear o receptor 5HT2 em relação ao D2, e uma afinidade muito mais alta pelo receptor $\mathrm{D} 4$ do que pelo $\mathrm{D} 2{ }^{46}$. A principal desvantagem desse medicamento é o risco de discrasia sanguínea, o que requer monitorização regular com hemograma completo. A clozapina aumenta a atividade do gene precoce-imediato $c$-fos no córtex pré-frontal, a região neuroanatômica que tem a concentração mais alta de receptores D4, sendo uma área que se acredita mediar as funções executivas específicas que são proeminentemente prejudicadas na esquizofrenia. Esses agentes são mais eficazes no tratamento dos sintomas psicóticos negativos da esquizofrenia, como apatia e anergia, e na melhora da função cognitiva ${ }^{45}$, além de ser mais efetivos para o tratamento de pacientes refratários. Os antipsicóticos podem causar uma ampla gama de efeitos colaterais, incluindo letargia, ganho ponderal, hipotensão postural, prisão de ventre, boca seca, aumento de secreção de prolactina, prolongamento do intervalo QTc no eletrocardiograma e discinesia tardia. O fator limitante mais frequente da posologia dos agentes antipsicóticos é o aparecimento de efeitos colaterais extrapiramidais, como distonia, acatisia e parkinsonismo. O tratamento farmacológico da esquizofrenia é insuficiente, sendo necessário um modelo de tratamento envolvendo uma equipe multidisciplinar.

\section{Considerações finais}

A importância do sistema de neurotransmissão colinérgica tem sido significativamente evidenciada, visto sua relação com algumas doenças do SNC. As alterações neuropsiquiátricas que envolvem disfunções desse sistema podem ser observadas em quadros patológicos atualmente de considerável incidência, como doença de Alzheimer. Neste trabalho, procurou-se ressaltar o entendimento desse sistema para permitir um tratamento mais específico para doenças de sintomatologias tão diversas, sendo ainda necessárias mais informações que orientem a geração de medicamentos mais específicos para o tratamento dessas patologias.

\section{Referências}

1. Bruneau EG, Akaaboune M. Running to stand still: ionotropic receptor dynamics at central and peripheral synapses. Mol Neurobiol. 2006;34(2):137-51

2. Fujii T, Takada-Takatori Y, Kawashima K. Basic and clinical aspects of non-neuronal acetylcholine: expression of an independent, non-neuronal cholinergic system in lymphocytes and its clinical significance in immunotherapy. J Pharmacol Sci. 2008;106(2):186-92.

3. Taylor P, Brown JH. Nicotinic receptors. In: Siegel GJ, Agranoff BW, Albers RW, editors. Basic neurochemistry: molecular, cellular, and medical aspects (Philadelphia): Raven Press; 1994. p. 248-54. 
4. Jósê AS, Franciscato C, Sonego F, Figueiró M, Thiesen FV, Garcia SC, et al. Sensitivity of young rats to nicotine exposure: Physiological and biochemical parameters. Ecotoxicol Environ Saf. 2009;72(1):242-7.

5. Dale HH. The action of certain esters and ethers of choline, and their relation to muscarine. J Pharmacol Exp Ther. 1914;6:147-90.

6. Cox BC, Marritt AM, Perry DC, Kellar KJ. Transport of multiple nicotinic acetylcholine receptors in the rat optic nerve: high densities of receptors containing $\alpha 6$ and $\beta 3$ subunits. J Neurochem. 2008;105(5):1924-38.

7. Millar NS, Gotti C. Diversity of vertebrate nicotinic acetylcholine receptors. Neuropharmacology. 2009;56(1):237-46.

8. Albuquerque EX, Pereira EF, Castro NG, Alkondon M, Reinhardt S, Schroder $\mathrm{H}$, et al. Nicotinic receptor function in the mammalian central nervous system. Ann NY Acad Sci. 1995;757:48-72.

9. Wang H, Sun X. Desensitized nicotinic receptors in brain. Brain Res Brain Res Rev. 2005;48(3):420-37.

10. Pacheco MA, Pastoor TE, Wecker L. Phosphorylation of the alpha4 subunit of human alpha4beta2 nicotinic receptors: role of cAMP-dependent protein kinase (PKA) and protein kinase C (PKC). Brain Res Mol Brain Res. 2003;114(1):65-72.

11. Gopalakrishnan M, Molinari EJ, Sullivan JP. Regulation of human alpha4beta2 neuronal nicotinic acetylcholine receptors by cholinergic channel ligands and second messenger pathways. Mol Pharmacol. 1997;52(3):524-34.

12. Quick MW, Lester RA. Desensitization of neuronal nicotinic receptors, J Neurobiol. 2002;53(4):457-78.

13. Albuquerque EX, Pereira EF, Alkondon M, Rogers SW. Mammalian nicotinic acetylcholine receptors: from structure to function. Physiol Rev. 2009;89(1):73-120.

14. Löscher W, Klotz U, Zimprich F, Schmidt D. The clinical impact of pharmacogenetics on the treatment of epilepsy. Epilepsia. 2009;50(1):1-23.

15. Zhou C, Wen ZX, Wang ZP, Guo X, Shi DM, Zuo HC, et al. Green fluorescent protein-labeled mapping of neural stem cells migrating towards damaged areas in the adult central nervous system. Cell Biol Int. 2003;27(11):943-5.

16. Langmead CJ, Watsona J, Reavilla C. Muscarinic acetylcholine receptors as CNS drug targets. Pharmacol Ther. 2008;117(2):232-43.

17. Riker WF, Wescoe WC. The pharmacology of flaxedil with observations on certain analogs. Ann Ny Acad Sci. 1951;54:373-94.

18. Barlow RB, Berry KJ, Glenton PAM, Nikolau NM, Soh KSA. A comparison of affinity constants for muscarine-sensitive acetylcholine receptors in guinea-pig atrial pacemaker cells at 29 degrees $\mathrm{C}$ and in ileum at 29 degrees C and 37 degrees C. Br J Pharmacol. 1976;58(4):613-20.

19. Van Koppen CJ, Nathanson NM. The cysteine residue in the carboxylterminal domain of the M2 muscarinic acetylcholine receptor is not required for receptor-mediated inhibition of adenylate cyclase. J Neurochem. 1991;57(6):1873-7.

20. Wess J. Molecular basis of muscarinic acetylcholine receptor function. Trends Pharmacol Sci. 1993;14(8):308-13.

21. Sandiford S, Slepak V. G5-RGS7 selectively inhibits muscarinic M3 receptor signaling via the interaction between the third intracellular loop of the receptor and the DEP domain of RGS7. Biochemistry. 2009;48(10):2282-9.

22. Caulfield MP. Muscarinic receptors-characterization, coupling and function. Pharmacol Ther. 1993;58(3):319-79.

23. Levey AI, Edmunds SM, Heilman CJ, Desmond TJ, Frey KA. Localization of muscarinic $\mathrm{M} 3$ receptor protein and $\mathrm{M} 3$ receptor binding in rat brain. Neuroscience. 1994;63(1):207-21.

24. Hamilton E, Nathanson NM. The M1 receptor is required for muscarinic activation of mitogen-activated protein (MAP) kinase in murine cerebral cortical neurons. J Biol Chem. 2001;276(19):15850-3.

25. Levey AI, Kitt CA, Simonds WF, Price DL, Brann MR. Identification and localization of muscarinic acetylcholine receptor proteins in brain with subtype-specific antibodies. J Neurosci. 1991;11(10):3218-26.
26. Wang YX, Dhulipala PD, Li L, Benovic JL, Kotlikoff MI. Coupling of M2 muscarinic receptors to membrane ion channels via phosphoinositide 3-kinase gamma and atypical protein kinase C. J Biol Chem. 1999;274(20):13859-64.

27. Wotta DR, Wattenberg EV, Langason RB, El-Fakahany EE. M1, M3 and M5 muscarinic receptors stimulate mitogen-activated protein kinase. Pharmacology. 1998;56(4):175-86.

28. Kimura F, Baughman RW. Distinct muscarinic receptor subtypes suppress excitatory and inhibitory synaptic responses in cortical neurons. J Neurophysiol. 1997;77(2):709-16.

29. Mita Y, Dobashi, K, Suzuki K, Mori M, Nakazawa T. Induction of muscarinic receptor subtypes in monocytic/macrophagic cells differentiated from eol-1 cells. Eur J Pharmacol. 1996;297(1-2):121-7.

30. Krupnick JG, Benovic JL. The role of receptor kinases and arrestins in G protein-coupled receptor regulation. Annu Rev Pharmacol Toxicol. 1998;38:289-319.

31. Scarselli M, Donaldson JG. Constitutive internalization of G proteincoupled receptors and $G$ proteins via clathrin-independent endocytosis. J Biol Chem. 2009;284(6):3577-85.

32. Chuang TT, Iacovelli L, Sallese M, De Blasi A. G protein-coupled receptors: heterologous regulation of homologous desensitization and its implications. Trends Pharmacol Sci. 1996;17(11):416-21.

33. Reinera C, Nathanson NM. The internalization of the M2 and M4 muscarinic acetylcholine receptors involves distinct subsets of small G-proteins. Life Sci. 2008;82(13-14):718-27.

34. Goodman OB, Krupnick JG, Gurevich VV, Benovic JL, Keen JH. Arrestin/ clathrin interaction. Localization of the arrestin binding locus to the clathrin terminal domain. J Biol Chem. 1997;272(23):15017-22.

35. Bernard V, Décossas M, Liste I, Bloch B. Intraneuronal trafficking of G-protein-coupled receptors in vivo. Trends Neurosci. 2006;29(3):140-7.

36. Cummings JL, Back C. The cholinergic hypothesis of neuropsychiatric symptons in alzheimer disease. Am J Geriatr Psychiatry. 1998;6:64-78.

37. Weinreb O, Mandel S, Bar-Am O, Yogev-Falach M, Avramovich-Tirosh Y, Amit T, et al. Multifunctional neuroprotective derivatives of rasagiline as anti-Alzheimer's disease drugs. Neurotherapeutics. 2009;6(1):163-74.

38. Clark CM, Karlawish JHT. Alzheimer disease: current concepts and emerging diagnostic and therapeutic strategies. Ann Intern Med. 2003;138(5):400-10.

39. Puttfarcken PS, Jacobs I, Faltynek CR. Characterization of nicotinic acetylcholine receptor-mediated [(3)H]-dopamine release from rat cortex and striatum. Neuropharmacology. 2000;39(13):2673-80.

40. Dani JA, Biasi MD. Cellular mechanisms of nicotine addiction. Pharmacol Biochem Behav. 2001;70(4):439-46.

41. Fiore MC. US public health service clinical practice guideline: treating tobacco use and dependence. Respir Care. 2000;45(10):1200-62.

42. Wang C, Xiao D, Chan KP, Pothirat C, Garza D, Davies S. Varenicline for smoking cessation: a placebo-controlled, randomized study. Respirology. 2009;14(3):384-92.

43. Oncken C, Gonzales D, Nides M, Rennard S, Watsky E, Billing CB, et al. Efficacy and safety of the novel selective nicotinic acetylcholine receptor partial agonist, varenicline, for smoking cessation. Arch Intern Med. 2006;166(15):1571-77.

44. Bymaster FP, Hemrick-Luecke SK, Perry KW, Fuller RW. Neurochemical evidence for antagonism by olanzapine of dopamine, serotonin, alpha 1 -adrenergic and muscarinic receptors in vivo in rats. Psychopharmacology. 1996;124(1-2):87-94.

45. Tandon R, Milner K, Jibson MD. Antipsychotics from theory to practice: integrating clinical and basic data. J Clin Psychiatry. 1999;60:21-8.

46. Tiihonen J, Wahlbeck K, Kiviniemi V. The efficacy of lamotrigine in clozapine-resistant schizophrenia: a systematic review and meta-analysis. Schizophr Res. 2009;109(1-3):10-4. 